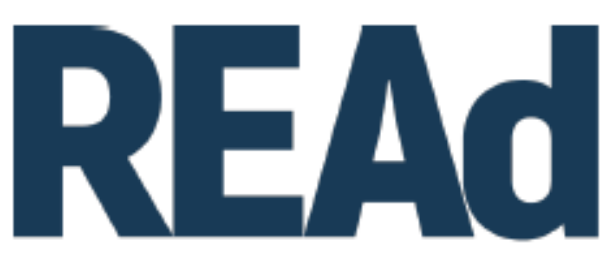

Revista Eletrônica de Administração

\title{
SUBPROCESSOS DE ENGAJAMENTO EM CULTURAS DE CONSUMO DE CERVEJAS ARTESANAIS ${ }^{1}$
}

\author{
João Menezes Filho ${ }^{2}$ \\ Minelle Enéas da Silva ${ }^{3}$ \\ Brunno Fernandes Silva Gaião ${ }^{4}$
}

http://dx.doi.org/10.1590/1413-2311.324.104967

\begin{abstract}
RESUMO
Esta pesquisa investiga a cultura de consumo de cerveja artesanal e os subprocessos de engajamento do consumidor identificados. Buscando identificar as categorias que suportam a existência de um efetivo engajamento, esta pesquisa gera discussão em relação à cognição, à emoção e ao comportamento dos consumidores. Por meio de uma pesquisa qualitativa, foram realizadas 32 entrevistas e 75 horas de observação direta participante. Os dados foram analisados de acordo com as dimensões selecionadas. Desse modo, foram observados como subprocessos de engajamento: (1) na dimensão cognitiva (aprendizado, advocacia e domínio do ritual); (2) na dimensão emocional (conexão, identificação e valores) e (3) na dimensão comportamental (lealdade, interação e co-criação). Uma vez cientes de tais processos é possível que gestores desenvolvam estratégias mais eficientes tanto de engajamento quanto de fortalecimento da comunidade de marca.
\end{abstract}

Palavras-chave: Cultura de consumo. Engajamento do consumidor. Subprocessos. Cerveja artesanal.

\footnotetext{
${ }^{1}$ Recebido em 30/6/2020, aceito em 13/4/2021.

${ }^{2}$ Universidade de Fortaleza (UNIFOR) - Programa de Pós-Graduação em Administração; Fortaleza - CE (Brasil) e Centro Universitário Inta (UNINTA); Sobral CE (Brasil); http://orcid.org/0000-0002-4323-1306; joaofilhobox@gmail.com.

${ }^{3}$ Universidade de Fortaleza - Programa de Pós-Graduação em Administração; Fortaleza - CE (Brasil); http://orcid.org/0000-0003-2074-6478; minele.adm@gmail.com.

${ }^{4}$ Universidade Estadual da Paraíba - Departamento de Administração e Economia; Campina Grande - Paraíba (Brasil); http://orcid.org/0000-0002-3843-7625; brunnogaiao@ gmail.com.
} 


\section{SUB-PROCESSES OF CONSUMER ENGAGEMENT IN THE CRAFT BEER CONSUMPTION CULTURES}

This research investigates the consumer culture of craft beer and the sub-processes of consumer engagement. Seeking to identify the categories that support the existence of effective engagement, this research generates discussion in relation to cognition, emotion and behavior of consumers. Through a qualitative research, 32 interviews and 75 hours of direct participant observation were carried out. Data were analyzed according to the selected dimensions. Thus, they were observed as sub-processes of engagement: (1) in the cognitive dimension (learning, advocacy and mastery of the ritual); (2) in the emotional dimension (connection, identification and values) and (3) in the behavioral dimension (loyalty, interaction and co-creation). Once aware of these processes, managers can develop more efficient strategies for both engagement and strengthening the brand community.

Keywords: Consumer culture. Consumer engagement. Sub-processes. Craft beer.

\section{SUBPROCESOS DE COMPROMISO EN CULTURAS DE CONSUMO DE CERVEZAS ARTESANALES}

Esta investigación investiga la cultura del consumo de cerveza artesanal y los subprocesos identificados de participación del consumidor. Buscando identificar las categorías que sustentan la existencia de un compromiso efectivo, esta investigación genera discusión en relación a la cognición, la emoción y el comportamiento del consumidor. Por medio de una investigación cualitativa, se realizaron 32 entrevistas y 75 horas de observación directa participante. Los datos se analizaron según las dimensiones seleccionadas. Así, se observaron como subprocesos de participación los siguientes: (1) en la dimensión cognitiva (aprendizaje, defensa y dominio ritual); (2) en la dimensión emocional (conexión, identificación y valores) y (3) en la dimensión conductual (lealtad, interacción y cocreación). Una vez que conocen estos procesos, los gerentes pueden desarrollar estrategias más eficientes tanto para el compromiso como para el fortalecimiento de la comunidad de la marca.

Palavras-clave: Cultura de consumo. Compromiso del consumidor. Subprocesos. Cerveza artesanal.

\section{INTRODUÇÃO}

A busca por entender as nuances em torno da prática de consumo e do envolvimento do consumidor tem se mostrado cada vez mais constante. Assim, uma vez que a ordenação social é definida, entre outras estruturas, em torno do consumo (ARNOULD; THOMPSON, 2005), as culturas de consumo da sociedade contemporânea estão sujeitas à moderação do mercado. $\mathrm{O}$ ato de consumir passou a invocar para si significados cada vez mais distantes dos benefícios funcionais antes observados, incorporando, de forma contínua, aspectos de identificação e de 
diferenciação por meio de seu uso (MCCRACKEN, 2003). Tais aspectos estão relacionados a subprocessos existentes nas culturas de consumo, e correspondem ao apoio a macroprocessos na sociedade (HARRINGTON, 1993). No caso do engajamento do consumidor, o macroprocesso estudado, os subprocessos se referem às experiências vivenciadas no ato de consumo que representam identificação e envolvimento.

Os aspectos simbólicos do consumo, em comparação aos seus aspectos funcionais (ESCALAS; BETTMAN, 2005), proporcionam ao consumidor uma maior propensão ao selfbrand connection, entendido como o grau em que os consumidores incorporam a marca em seu autoconceito (ESCALAS; BETTMAN, 2003). Esse fato determina o estilo de vida do indivíduo e o caracteriza mediante os grupos dos quais faz parte. Neste sentido, as pessoas têm uma predisposição para rotularem a si e aos demais (BAGOZZI; DHOLAKIA, 2006). Além disto, em muitas ocasiões, a percepção de pertencimento está relacionada aos grupos de consumidores que compartilham um conjunto de afinidades sociais com base na utilização de uma marca: as comunidades de marca (SCHOUTEN et al., 2007; FÜLLER et al., 2008; SCHAU et al., 2009). Assim, assumindo que uma cultura de consumo se estabelece enquanto um conjunto de artefatos, significados e práticas compartilhadas por um grupo a partir de um contexto de troca comercial (KOZINETS, 2001), esta depende das relações em torno do objeto que está sendo investigado, bem como do envolvimento do consumidor.

O envolvimento com marcas e produtos é um conceito que deve ser combinado com elementos como atenção, diálogo, interação, emoções, prazer sensorial, e ativação imediata com o objetivo de criar uma experiência de marca total com consumidores. Com isso, as empresas começam a perceber o engajamento com o cliente como um importante fator que pode moldar a preferência do cliente pela escolha de determinado produto (GAMBETTI et al., 2012). O engajamento é multidimensional (cognitivo, emocional e comportamental) (BRODIE et al., 2010; SILVA; CAMPOS, 2020). Dessa forma, percebe-se uma conexão entre engajamento do consumidor e valores simbólicos dos bens de consumo, e tal conexão vai além das transações, e resulta de forças motivacionais. Como o foco desta pesquisa são os subprocessos, vale salientar que Brodie et al. (2013), propõem cinco subprocessos do engajamento do consumidor: aprendizado, compartilhamento, advocacia, socialização e codesenvolvimento, adicionando fatores internos ao seu modelo conceitual de processo de engajamento do consumidor. Apesar disso, os subprocessos são pouco estudados na literatura.

Assumindo que o engajamento do consumidor pode ser trabalhado nos mais diversos segmentos do mercado, esta pesquisa se debruça sobre a indústria cervejeira, mais 
especificamente no setor das cervejas artesanais, que configura uma cultura de consumo específica (ver KOZINETS, 2001). Em comparação com os consumidores das cervejas industriais, os apreciadores de cervejas artesanais apresentam maior interesse pela história do produto, procuram entender mais sobre os ingredientes e sobre a produção, buscam mais conhecimento, além de sentirem prazer em divulgar o produto, compartilhar informações, e, assim, atrair novos consumidores (BELTRAMELLI, 2015; MORADO, 2017). Diante do crescente mercado de cerveja artesanal e do fortalecimento dessa cultura de consumo (MAPA, 2020), e assumindo o conceito de engajamento como elemento importante para tal, definimos a seguinte pergunta de pesquisa: Como cada uma das três dimensões (cognitiva, emocional e comportamental) suporta o engajamento do consumidor de cervejas artesanais?

Para tanto, uma pesquisa qualitativa foi desenvolvida em Fortaleza, Ceará, no sentido de desvendar quais subprocessos estão atrelados a cada uma das dimensões selecionadas. Do ponto de vista gerencial, essa pesquisa se justifica porque as empresas avaliam o engajamento como um imperativo estratégico para construir vantagem competitiva (BRODIE et al., 2011; HOLLEBEEK, et al., 2011). Vale ressaltar que, em 2010, o tema foi apontado como umas das prioridades de pesquisa pelo Marketing Science Institute (MSI). Cerca de dez anos depois, Obilo et al. (2020) apontam como o engajamento se tornou um tema bastante discutido na academia, contudo, não tendo sido esgotado, ainda demanda maior investigação e aprofundamento. Tal fato ressalta a relevância desta pesquisa.

No que concerne à atividade de consumo abordada nesta pesquisa, dados do Ministério da Agricultura, Pecuária e Abastecimento (MAPA, 2020) demonstram que entre os anos de 2008 e 2020 o número de cervejarias artesanais no Brasil saltou de 70 para quase 1.171. Com base no ritmo dos últimos períodos, tem-se uma taxa média de 19\%: nos últimos dez anos, 26\%, e, nos últimos cinco anos, $36 \%$. No que versa sobre o número de registros de produto, a cerveja continua sendo o produto mais registrado no MAPA alcançando o número de 9.950 registros, bem à frente do segundo lugar, polpa de fruta com 2.535, e dos demais, tais como o vinho, com 1.676 registros. Sendo assim, o crescimento do consumo de cerveja artesanal e o espaço que esse tipo de produto vem ocupando no setor, constituem uma arena fértil à realização de estratégias e táticas de relacionamento entre marcas e consumidores.

A presente pesquisa enriquece a literatura de cultura de consumo, conjugada predominantemente às técnicas interpretativistas (GAIÃO et al., 2012) e começa a se consolidar no Brasil (SOUZA et al., 2013), na medida em que sugere a existência de uma cultura de consumo relacionada à cerveja artesanal. Ao apresentar os subprocessos atrelados a cada 
dimensão, esta pesquisa aponta de que forma o engajamento do consumidor influencia a cultura de consumo de cervejas artesanais. Por fim, a presente pesquisa colabora para o desenvolvimento de estudos sobre o engajamento do consumidor, mais especificamente mediante à proposição de uma discussão que sugere a relação do engajamento do consumidor com perfis de consumidores pertencentes à cultura de consumo de cervejas artesanais.

\section{SUBCULTURAS DE CONSUMO: UM OLHAR A PARTIR DA CONSUMER CULTURE THEORY (CCT)}

$\mathrm{O}$ ato de consumir faz parte do cotidiano do homem desde os primórdios de sua existência, sendo entendido como um dos mais relevantes fenômenos do mundo moderno (MCCRACKEN, 2003; BARBOSA, 2006; DESJEUX, 2011). A Consumer Culture Theory (CCT) enxerga o ato de consumir como um fenômeno cultural, diferentemente da perspectiva psicológica ou econômica (ARNOULD; THOMPSON, 2005). Nesta pesquisa, foca-se nas "culturas de mercado" que investiga a forma como alguns produtos e experiências podem unir grupos em espécies de culturas ou subculturas de consumo (DINIZ; SILVA, 2017; OLIVEIRA et al., 2018). Entende-se como consumidores forjam sentimentos de vínculos sociais e criam universos culturais distintos, fragmentados, escolhidos por intermédio de interesses comuns de consumo (SCHOUTEN; MCALEXANDER, 1995; KOZINETS, 2001).

Neste contexto, entende-se uma subcultura de consumo como um subgrupo diverso da sociedade que se auto seleciona fundamentado em um compromisso compartilhado com uma atividade de consumo, uma marca, ou ainda uma classe de produto (SCHOUTEN; MCALEXANDER, 1995). Para tais autores, uma subcultura abrange um arcabouço hierárquico identificável, um ethos (conjunto de atitudes, crenças e valores) singular, assim como rituais, linguagem e modos únicos de expressão simbólica (OLIVEIRA et al., 2018). Tal conceituação é similar a de cultura de mercado apresentada por Arnould e Thompson (2005), na qual os consumidores desenvolvem sentimento de solidariedade social e concebem ambientes culturais distintos, fragmentados, auto selecionados por intermédio da procura por preferências de consumo afins, o que podem ser relacionados a subprocessos.

No que concerne ao uso de alguns termos da CCT, Kozinets (2001), assim como entendem outros autores, como Thornton (2018), critica a utilização da expressão subcultura, isto porque o termo pode ser entendido como uma cultura subalterna e dependente de uma cultura dominante. Kozinets (2001) recomenda então a utilização da expressão cultura de consumo para conceituar um conjunto conexo de imagens, textos e objetos comercialmente (c) (1) @ REAd | Porto Alegre - Vol. 27 - N.o 2 - Maio / Agosto 2021 - p. 547-578. 
produzidos que grupos utilizam, por intermédio da construção de práticas, identidades e significações sobrepostas, e/ou até mesmo contraditórias, para guiar as experiências e as vidas de seus membros.

Dessa forma, esses grupos irão influenciar de alguma maneira suas atitudes de consumo (SOLOMON, 2010), pois atuam como inspiração ou comparação pelo indivíduo, e por isso serão também conhecidos como grupos de referência. No momento em que um grupo de referência é criado em função de uma marca ou produto, tem-se o nascimento do que é entendido por comunidade de marca (DHOLAKIA et al., 2009). A expressão comunidade de marca possui inúmeras definições: uma coletividade de consumidores que partilha um conjunto de vínculos sociais baseados na utilização ou no interesse por um produto (MAFFESOLI, 1996; MUÑIZ Jr.; SCHAU, 2005); um grupo que possui como alicerce um conjunto de vínculos individuais entre os proprietários de uma marca e o vínculo psicológico que eles possuem com a marca em si, com o bem ou serviço utilizado e com a organização (MCALEXANDER et al., 2002).

Para Cova e Pace (2007), uma comunidade de marca é constituída por uma coletividade de pessoas que partilham uma afinidade por uma marca, ou por um produto específico, e concebem um universo paralelo com suas próprias crenças, rituais, valores, linguagens, vocábulos e hierarquia. Fournier e Lee (2009) corroboram esse entendimento quando afirmam que tais indivíduos constituem um grupo de consumidores que se estabelecem ao redor de um modo de vida semelhante, de atividades em comuns e do ethos de uma marca ou produto. Fazer parte de uma comunidade de marca conduz consumidores a desenvolverem condutas similares, as quais são definidas aqui como subprocessos. A força de uma comunidade de marca e a integração de um cliente nesta comunidade, reside em uma teia de relacionamentos que os clientes percebem ter com uma marca, uma empresa, um produto e seus outros clientes (SCHOUTEN et al., 2007), a partir da sua identificação e do seu envolvimento.

Com base nas definições anteriores, pode-se entender a comunidade de marca como uma coletividade cujos alicerces de identificação primária são produtos, marcas ou atividades relativas ao consumo, ou seja, cuja significação é negociada por intermédio do simbolismo do mercado. Desta forma, as comunidades de marca simbolizam um contexto social em que o vínculo entre os lados envolvidos é central. Dentre os relacionamentos essenciais incluem-se as interações do consumidor com a marca, com a organização, com o produto em uso e com os demais indivíduos da comunidade (MCALEXANDER et al., 2002) 
Além dos vínculos, notam-se outros aspectos basilares intrínsecos a uma comunidade de marca. Fundamentalmente, esses grupos são caracterizados pela consciência compartilhada, ou seja, pela sensação de conexão à marca ou produto, e aos demais indivíduos da comunidade (MUÑIZ; O'GUINN, 2001). Outro aspecto decisivo das comunidades de marca são seus rituais e suas tradições. Esses subprocessos são responsáveis pela reprodução e pela comunicação dos significados da comunidade. Apesar desta noção, ainda são poucas as pesquisas que estudam tais subprocessos como essenciais para entender as (sub)culturas de consumo.

A última característica basilar de uma comunidade de marca é o entendimento de responsabilidade moral. Conforme Muñiz e O’Guinn (2001), tal entendimento de responsabilidade é determinado como a sensação de obrigação para com o grupo pertencente como um todo e para com os seus membros, que se configura por intermédio da inclusão e da manutenção de membros e pelo auxílio ao consumo da marca ou produto. No âmbito das comunidades de marca, a procura por legitimidade, o reconhecimento dos pares e o fortalecimento social são vantagens que não podem ser totalmente alcançados sem um engajamento mais intenso (MARCHI et al., 2011).

$\mathrm{O}$ engajamento tem como consequência intensificar manifestações características da comunidade de marca. Quanto maior o engajamento na comunidade, maior será o sentimento de consciência compartilhada, maior será o conhecimento de rituais e tradições e maior será o senso de responsabilidade social/moral, características que definem uma comunidade (MADUPU; COOLEY, 2010a). Além disso, maior será também a integração com a marca, com o produto, com a empresa e com os demais consumidores da marca (MCALEXANDER et al., 2002). Uma vez que o engajamento nas comunidades de marca é centrado nas experiências interativas dos consumidores (BRODIE et al., 2013), as empresas que desejam aumentar o engajamento dos consumidores nas comunidades deveriam fomentar oportunidades para que relacionamentos interpessoais possam ocorrer com mais frequência (LEE; CHANG, 2011). Aqui se revela premente a necessidade de melhor compreender o engajamento do consumidor e seus subprocessos, principalmente para identificar como tais subprocessos afetam as subculturas de consumo da qual fazem parte.

\section{ENGAJAMENTO DO CONSUMIDOR}

As pesquisas de Vivek (2009), Van Doorn et al. (2010), Brodie et al. (2011) e Hollebeek (2011a) contribuem de maneira relevante para o enriquecimento do pensamento sobre engajamento dentro do campo de pesquisa do Marketing (MARRA; DAMACENA, 2013). Para 
Vivek (2009), o engajamento do consumidor aponta para o envolvimento a longo prazo, por meio da constituição duradoura de vínculos com os indivíduos e a evolução de afeição no processo, que colabora com o convertimento de virtuais consumidores em consumidores de fato, além de fortalecer o nível de entusiasmo dos consumidores existentes. O vínculo existente entre objeto de consumo e consumidor é entendido como o ponto central do engajamento do consumidor, não no que se refere à simples troca objetiva de bens de consumo, mas sim no que diz respeito à experiência do consumidor.

Van Doorn et al. (2010) procuraram evidenciar o Comportamento de Engajamento do Cliente (CEC) como um constructo e buscaram entender como, e por qual motivo, o comportamento dos clientes varia de forma relevante no que se refere à organização e seus diversos stakeholders. Sendo assim, criaram um modelo que permite entender essas condutas e analisá-las de maneira integrada (VAN DOORN et al., 2010). Partindo de uma ótica comportamental, caso os esforços do CEC sejam bem-sucedidos, os clientes se envolverão com mais constância e mais intimamente nessas ações.

Pensando na relação que pode ser estabelecida entre os integrantes da comunidade e as organizações produtoras, de acordo com o pensamento de van Doorn et al. (2010), consumidores engajados contribuem também em longo prazo para a share of mind, como foi demonstrado em sua participação em comunidades de marca e em eventos de apoio pertinentes à marca. Consumidores profundamente engajados podem se tornar uma relevante fonte de conhecimento, posto que auxiliam as organizações em uma multiplicidade de atividades, que englobam desde ideias para a criação e o desenvolvimento de novos produtos, sugestões para transformar marcas já vigentes, e até mesmo no teste de um produto desenvolvido (STORY et al., 2009).

Dessa forma, consumidores engajados podem sustentar e alimentar vínculos com outros consumidores, marcas, organizações e reguladores, independentemente da empresa focal, e podem exercer poderosa influência sobre a empresa focal e sua marca (VAN DOORN et al., 2010). De acordo com Brodie et al. (2011), as origens conceituais do engajamento do cliente podem ser elucidadas mediante o modelo da teoria dirigida à experiência interativa e à cocriação de valores nas relações de marketing. Sua colaboração é realizada por meio do fornecimento de uma apreciação mais extensa e mais rigorosa da definição teórica de engajamento do cliente, com o intuito de definir seu domínio conceitual.

Para Brodie et al. (2011), o engajamento do cliente pode ser conceituado como uma condição psicológica que acontece mediante interatividade e cocriação experiencial do cliente 
com objeto focal, dentro de uma relação focal de serviço. Isto acontece mediante um conjunto específico de condições em uma determinada situação. Assim, são criados múltiplos graus de engajamento do cliente, num procedimento interativo inserido nas relações de cocriação de valor. Nesta definição, vale enfatizar a ótica multidimensional do engajamento do cliente, em outras palavras, as dimensões cognitiva, emocional, e/ou comportamental.

As expressões conceitualizações de engajamento elaboradas por Vivek (2009) e por Brodie et al. (2011) manifestam-se de forma semelhante. No entendimento de Vivek (2009), a participação e a conexão são predicados centrais para o engajamento do consumidor, porém, conforme a pesquisadora, a conexão acontece mediante relevantes interações com o consumidor e a participação e é pertinente ao âmbito da cocriação e coprodução.

Brodie et al. (2011), por outro lado, enfatizam que o engajamento acontece por meio da interatividade e da cocriação experiencial do cliente. Portanto, pode-se enxergar uma afinidade entre a expressão conexão sugerido por Vivek (2009), que afirma que as interações são ensejos para desenvolver relações com o consumidor, e a expressão de interatividade sugerida por Brodie et al. (2011), entendida como os meios de interação entre cliente e organização.

Existe ainda uma afinidade entre a expressão "participação" citada por Vivek (2009), enfatizada pela pesquisadora por meio da cocriação e coprodução, e a expressão "cocriação de experiência" apresentada por Brodie et al. (2011), e conceituada como o grau de percepção de valor concebido na mente do cliente em consequência de atividades interativas, conjuntas e ou personalizadas para e com os stakeholders (DALL'OLMO; CHERNATONY, 2000; PRAHALAD; RAMASWAMY, 2004). Tais entendimentos não esclarecem quais são elementos (aqui chamados subprocessos) que forma o engajamento em detalhe, para além dos subprocessos apresentados a seguir. É necessário identificar para cada dimensão como engajar o consumidor. Neste ponto é válido ressaltar que o engajamento pode ser estabelecido dentro de uma comunidade não apenas com uma marca específica, mas também com uma classe de produtos. Neste sentido, a seguir será abordada uma perspectiva multidimensional do engajamento do consumidor voltada para a sua relação com um possível produto.

\subsection{PERSPECTIVA MULTIDIMENSIONAL DO ENGAJAMENTO DO CONSUMIDOR}

A mensuração do engajamento por meio de estudos empíricos enfatiza a existência de três dimensões: a dimensão cognitiva afetiva composta pelo entusiasmo, a dimensão da experiência, composta pela conscientização e a ação, e finalmente a dimensão social, composta pela interação (VIVEK, 2009). Entender o engajamento como um constructo multidimensional (c) (1) @ REAd | Porto Alegre - Vol. 27 - N.o 2 - Maio / Agosto 2021 - p. 547-578. 
é uma constante sobre esse conceito (HOLLEBEEK et al., 2014; 2019), abrangendo aspectos cognitivos, emocionais e comportamentais. O estado de engajamento pode ser observado de maneira contínua, considerando (1) desengajado - quando não há experiência de interação do cliente ou mesmo da organização; (2) pouco engajado - quando há baixo nível de comprometimento comportamental, cognitivo e emocional; (3) engajado - quando há amplo nível de comprometimento comportamental, cognitivo e emocional; e (4) altamente engajado quando há alto nível de comprometimento comportamental, cognitivo e emocional com as experiências interativas propostas (BRODIE et al., 2011).

Brodie et al. (2011) entende o engajamento como um estado motivacional que ocorre em virtude da interação e cocriação de experiências. Brodie et al. (2011) entende a cocriação de experiência como uma noção mais característica para o vínculo entre consumidor e empresa. Dessa forma, a noção integradora está presente nas conceituações de engajamento propostas por Vivek (2009), Vivek et al. (2012) e Brodie et al. (2011), como sendo a intensidade da cocriação de experiência e conexão do indivíduo com as ofertas ou atividades organizacionais, as quais podem ser iniciadas tanto pela organização quanto pelo indivíduo.

É importante ponderar que o nível de comprometimento durante o engajamento varia de acordo com o objeto, consumidor e contexto (BRODIE et al., 2013). Os autores identificam cinco subprocessos que acontecem de maneira frequente e dinâmica, não possuindo um fluxo exato para sua evolução. Tais subprocessos podem ser considerados como basilares para o entendimento dos subprocessos, como proposto na presente pesquisa. Para melhor compreensão, segue detalhamento de cada um:

1. Aprendizado: é entendido pela obtenção indireta de aptidões cognitivas que o consumidor aplica na aquisição de um bem de consumo, ou ainda durante o processo de tomada de decisão;

2. Compartilhamento: este aspecto espelha as dimensões de conduta e cognição em uma comunidade, uma vez que o consumidor partilhe suas noções sobre o tema em questão. Ao difundir o conhecimento, colabora para a coconstrução de valor da comunidade;

3. Advocacia: acontece quando um consumidor ou um grupo ativamente e repetidamente indica certo bem de consumo, seja ele produto, serviço ou marca. Também é considerado quando há indicação sobre a melhor forma de se utilizar o bem de consumo, reforçando ainda mais o compartilhamento; 
4. Socialização: aponta para senso de pertencimento e comunidade, tendo relação com a teoria da identidade social (TAJFEL; TURNER, 1985). Esse subprocesso pode ser identificado quando é possível perceber que há normas estabelecidas, linguagem específica dentro da comunidade e declarações pessoais entre os membros;

5. Codesenvolvimento: subprocesso no qual os consumidores colaboram com a organização no incremento e melhoria de bens de consumo, marcas e outras formas de oferta.

Dado o exposto, para a presente pesquisa tais subprocessos irão auxiliar a identificar quais subprocessos compõem a cultura de consumo de cerveja artesanal. É relevante lembrar que, na literatura pesquisada, expressões correspondentes, como participação e interação, são amplamente utilizadas possuindo a mesma finalidade de significação, contudo, o engajamento, como apontado especialmente pelos pesquisadores Vivek (2009), Van Doorn et al. (2010), Hollebeek (2011) e Brodie et al. (2011), é um procedimento complexo e ininterrupto de experiência de consumo moderado pela cocriação de valor entre consumidores e marcas. No âmbito das comunidades de marca, o engajamento diz respeito às motivações para interagir e contribuir com os membros da comunidade, em outras palavras, subentende-se que os membros estejam interessados em auxiliar uns aos outros, participar em atividades conjuntas, agir voluntariamente para endossar e valorizar o seu valor e de outros (ALGESHEIMER et al., 2005). Com base nessa discussão, a presente pesquisa possui caráter qualitativo e pretende responder aos gaps de pesquisa existentes.

\section{PROCEDIMENTOS METODOLÓGICOS}

Considerando que esta pesquisa busca identificar quais são os subprocessos que suportam o engajamento do consumidor de cervejas artesanais em Fortaleza, considerou-se os aspectos apresentados por Cooper e Schindler (2003) no que concerne às estratégias do planejamento para as pesquisas em administração. Assim sendo, pode-se classificar esta pesquisa como: exploratória e descritiva, de natureza qualitativa.

\subsection{O CENÁRIO CERVEJEIRO NACIONAL}

Conforme os dados do Sindicato Nacional da Indústria da Cerveja (2020), o Brasil é o terceiro maior fabricante mundial, com 13,3 bilhões de litros. De acordo com a Associação Brasileira de Cerveja Artesanal (ABRACERVA) (2018), a cerveja é a bebida alcoólica favorita (c) (1) @) REAd | Porto Alegre - Vol. 27 - N. o 2 - Maio / Agosto 2021 - p. 547-578. 
de dois terços dos brasileiros para celebrações, com $64 \%$ da preferência. A Brewer's Association (2018) define cervejarias artesanais com base em três critérios: a cervejaria deve ser pequena (produção inferior a seis milhões de barris de cerveja por ano), independente (não detida por uma empresa de bebidas alcoólicas) e as cervejas provêm de tradição para ingredientes inovadores na produção de cerveja. Dados divulgados pelo Ministério da Agricultura, Pecuária e Abastecimento (2018) apontam um crescimento de aproximadamente 19\% no número de cervejarias artesanais registradas no Brasil em 2018, o equivalente a 835, já em 2017 só existiam 679 cervejarias. Em julho de 2019, essa marca ultrapassou as 1000 cervejarias registradas.

\subsection{CONSTITUIÇÃO E ANÁLISE DO CORPUS DE PESQUISA}

Foram selecionadas como técnicas de coleta de dados entrevistas semi-estruturadas e observações participantes. Isso foi possível uma vez que um dos pesquisadores possui envolvimento com o cenário cervejeiro na cidade de Fortaleza, o que se alinha com a proposta de Mattar (2014), ao se afirmar que a experiência, o conhecimento e a sensibilidade do pesquisador são fundamentais para a determinação correta de que instrumento será mais adequado para cada pesquisa específica.

Para a seleção dos entrevistados utilizou-se como critério o consumo de cervejas artesanais ao menos uma vez por mês nos seis meses anteriores à pesquisa. Acredita-se que o consumo mensal de cervejas artesanais, na frequência e período estipulados, caracteriza o hábito de consumo desse produto, excluindo assim consumidores eventuais da bebida. Adicionalmente, foi utilizada a técnica de snowball para selecionar os entrevistados. As entrevistas individuais possibilitaram uma comunicação direta, bidirecional, por meio da qual coletou-se as informações referentes ao tema pesquisado. Essa técnica tem como vantagem basilar a ampla flexibilidade para adaptações ou alterações de rumo ao longo do processo, caso o condutor se depare com novas descobertas ou fatos de real importância para o resultado que se busca.

Neste estudo, os sujeitos pesquisados foram consumidores de cervejas artesanais, homens e mulheres, maiores de dezoito anos, residentes na cidade de Fortaleza. A pesquisa ocorreu entre os meses de setembro e outubro de 2018. Foram realizadas 32 entrevistas, totalizando cinco horas de gravação, com média de treze minutos por entrevista. No que concerne ao gênero dos entrevistados, a maioria dos pesquisados foram do sexo masculino totalizando 23 homens. Apenas 9 mulheres foram entrevistadas. Nota-se per meio de uma (c) $(1) \Theta$ 
análise do perfil sociodemográfico que o corpus foi composto por pessoas com diversas ocupações, incluindo a presença de profissionais do setor cervejeiro.

Tendo em vista a subjetividade e a complexidade do tema pesquisado, para a condução das entrevistas, utilizou-se um roteiro de entrevista elaborado com base na literatura. $\mathrm{O}$ roteiro foi constituído por uma série de perguntas que envolve desde motivações, crenças, atitudes e hábitos, até sentimentos que englobam o tema da pesquisa. A coleta de dados aconteceu em um ambiente sem restrições, normalmente o próprio contexto da cervejaria, facilitando estimular o entrevistado a discorrer sobre um assunto específico, compartilhando o máximo de dados possíveis e expondo características relacionadas a sua prática de consumo.

A observação participante também ocorreu durante os meses de setembro e outubro de 2018 em diversos estabelecimentos e eventos relacionados à cerveja artesanal. Com o intuito de captar uma variedade de situações que extrapolavam o contexto das entrevistas, foi elaborado um roteiro com o objetivo de descrever o que foi observado na pesquisa. Durante um total de noventa e cinco horas de observação foi utilizado um diário de campo para registros. Mediante a manutenção do diário de campo, buscou-se autodisciplina ao observar e anotar sistematicamente o contexto e as relações inerentes aos consumidores de cerveja artesanal.

O roteiro da observação, similar ao definido para o roteiro de entrevistas, tinha como objetivo observar aspectos cognitivos, emocionais e comportamentais referentes ao consumo de cervejas artesanais. Foram levados em consideração aspectos como a existência de algum tipo de influência de outros consumidores na escolha da cerveja consumida, rituais de compra e consumo, a expressão corporal quando o consumidor gostava ou não da cerveja consumida, como se dava a escolha da cerveja consumida e com quem preferiam apreciar cerveja artesanal, se existia algum preconceito entre os tipos de consumidores de cerveja artesanal, e do mesmo modo, se existia algum tipo de hierarquia entre os consumidores. A observação desses subprocessos auxiliou o entendimento de como engajamento se constitui na cultura de consumo de cervejas artesanais na cidade de Fortaleza.

O procedimento de análise, se deu por meio da técnica de análise de conteúdo (BARDIN, 2009) para o tratamento e a interpretação dos dados obtidos durante o estudo realizado. As entrevistas foram gravadas e, posteriormente, transcritas. Já a observação participante foi representada por meio de diários de campo, o que resultou na constituição do "corpus" documental a ser analisado. A análise foi realizada por meio da combinação das abordagens dedutiva e indutiva (Mayring, 2004). Em sua maioria, os subprocessos identificados se referem especificamente à cultura de consumo de cerveja artesanal, no entanto, é possível 
identificá-los relacionados aos aspectos teóricos utilizados durante a pesquisa. Foi realizada uma leitura flutuante do material, estabelecendo-se um código para cada uma das entrevistas, com o intuito de preservar a identidade dos indivíduos entrevistados.

No que que diz respeito aos critérios de qualidade na pesquisa, neste estudo foram adotados os seguintes critérios de validade e confiabilidade: triangulação de técnicas de coleta, clareza nos procedimentos e descrição rica e detalhada. Já no que concerne as questões éticas da pesquisa, houve o detalhamento da pesquisa para os participantes. Dessa forma, os sujeitos tinham a opção de aderir voluntariamente (por meio de termo de consentimento), ou não, às entrevistas, cônscios da natureza do estudo e das obrigações nele envolvidos. Com o intuito de preservar a identidade dos entrevistados, cada participante foi representado por um código de identificação.

\section{RESULTADOS}

O engajamento do consumidor é um tema de conceito multidimensional para um contexto e/ou stakeholder específico, expressando relevantes dimensões cognitivas, emocionais e comportamentais (BRODIE et al., 2011). Isto posto, na pesquisa identificou-se subprocessos de engajamento dos consumidores de cerveja artesanal com base nas variáveis cognitiva, emocional e/ou comportamental (BRODIE et al., 2011).

\subsection{DIMENSÃO COGNITIVA}

A dimensão cognitiva envolve o estado de estar consciente e ter conhecimento do foco do engajamento (BRODIE et al., 2011). A cognição envolve fatores diversos como o pensamento, a linguagem, a percepção, a memória, o raciocínio etc., que fazem parte do desenvolvimento intelectual. Conforme os trechos analisados no Quadro 1, pode-se dividir a dimensão cognitiva referente aos consumidores de cerveja artesanal na cidade de Fortaleza em três subprocessos: aprendizado, advocacia e domínio do ritual.

Aprendizado é entendido pela obtenção indireta de aptidões cognitivas que o consumidor aplica em na aquisição de um bem de consumo, ou ainda durante o processo de tomada de decisão (BRODIE et al., 2011). Para esse subprocesso, foram abordadas questões sobre o nível de conhecimento dos entrevistados, sua fonte de conhecimento, além de como esse conhecimento é utilizado. 
A advocacia acontece quando um consumidor ou um grupo ativamente e repetidamente indica certo bem de consumo, seja ele produto, serviço ou marca. Também é considerado quando há indicação sobre a melhor forma de se utilizar o bem de consumo, reforçando ainda mais o compartilhamento (BRODIE et al., 2011). Neste subprocesso foram realizadas perguntas que buscavam entender se o entrevistado influencia demais pessoas e os motivos que o leva a isso.

Rituais e tradições são os processos sociais vitais para que ocorra a reprodução e transmissão interna e externa dos significados dessa comunidade, a partir da celebração e do compartilhamento de histórias da marca (MUÑIZ JR.; O'GUINN, 2001). Para entender esse subprocesso, foram feitos questionamentos sobre os hábitos de consumo dos entrevistados.

Quadro 1 - Dimensão cognitiva.

\begin{tabular}{|c|c|c|}
\hline Subprocesso & Definição & Trecho selecionado \\
\hline \multirow{3}{*}{ Aprendizado } & \multirow{3}{*}{$\begin{array}{c}\text { Aquisição de } \\
\text { competências } \\
\text { cognitivas } \\
\text { aplicadas na } \\
\text { decisão de } \\
\text { compra e } \\
\text { consumo. }\end{array}$} & $\begin{array}{l}\text { "Eu não posso dizer que sou um profundo conhecedor, tem gente que } \\
\text { sabe bem mais do que eu, ainda não eu não tenho estudo pra isso, mas } \\
\text { quando eu tenho alguns amigos que sabem que consumo cerveja } \\
\text { artesanal e se interessam eu tenho o maior prazer em levar para um } \\
\text { tap room, para mostrar as cervejas." (E6) }\end{array}$ \\
\hline & & $\begin{array}{l}\text { "Eu me considero aprendiz do produto até porque tem pouco tempo } \\
\text { que eu tenho envolvimento com cerveja ou com qualquer bebida." } \\
\qquad(\mathrm{E} 10)\end{array}$ \\
\hline & & $\begin{array}{l}\text { "Busco aprender mais principalmente com amigos que são } \\
\text { conhecedores, a mesa de bar é uma ótima escola. Além disso, com } \\
\text { formadores de opinião nas redes sociais, sem esquecer que livros e } \\
\text { cursos são sempre bem-vindos." (E16) }\end{array}$ \\
\hline \multirow[b]{2}{*}{ Advocacia } & \multirow{2}{*}{$\begin{array}{l}\text { Defesa do } \\
\text { produto, } \\
\text { recomendação } \\
\text { ativa da marca. }\end{array}$} & $\begin{array}{l}\text { "Rapaz, eu me senti, quando eu influencio outra pessoa, acho que } \\
\text { cumprindo um papel, eu que trabalho nessa área, eu tenho além do } \\
\text { papel de produzir, eu tenho que divulgar a cultura cervejeira." (E1) }\end{array}$ \\
\hline & & $\begin{array}{l}\text { "Eu tento influenciar as pessoas mostrando, introduzindo rótulos mais } \\
\text { simples inicialmente, ensinando como beber, qual a temperatura, qual } \\
\text { o copo, essas coisas. Tento ser um catequizador sem ser um chato." } \\
\text { (E8) }\end{array}$ \\
\hline
\end{tabular}




\begin{tabular}{|c|c|c|}
\hline & & $\begin{array}{c}\text { "Quero que essas pessoas descubram um mundo novo, que tenham as } \\
\text { mesmas experiências que eu tive, é como se eu quisesse catequizar } \\
\text { essas pessoas no mundo das cervejas boas." (E16) }\end{array}$ \\
\hline \multirow{3}{*}{ Domínio do ritual } & \multirow{3}{*}{$\begin{array}{c}\text { Transmissão } \\
\text { interna e externa } \\
\text { dos significados } \\
\text { da comunidade }\end{array}$} & $\begin{array}{l}\text { "O ritual é que eu sempre busco beber no copo certo ou no copo da } \\
\text { marca da cerveja." (E9) }\end{array}$ \\
\hline & & $\begin{array}{l}\text { "Na hora da compra eu primeiro leio o rótulo, vejo qual é a } \\
\text { cervejaria, se vale a pena ou não apreciar, depois tomo cuidado com o } \\
\text { copo, temperatura, harmonização. Depende muito do dia. Se for beber } \\
\text { mais de uma, tendo de seguir uma ordem de intensidade." (E16) }\end{array}$ \\
\hline & & "Não tenho nenhum ritual.” (E18) \\
\hline
\end{tabular}

Fonte: Dados de Pesquisa (2020).

Com base nos trechos do quadro anterior, toma-se como foco o aprendizado, pode-se afirmar que está relacionado com o momento da compra e do consumo, o apreciador de cerveja artesanal utiliza o conhecimento que possui a respeito do produto, para escolher a cerveja mais adequada para seu paladar, ou para degustar e harmonizar da maneira correta. Além disso, podese confirmar que as aptidões cognitivas também são utilizadas para influenciar ou ajudar outros indivíduos a experimentar o produto. Vale ressaltar que existe a percepção de níveis de aprendizado, bem como a percepção, de bares e casas especializadas, como uma das mais relevantes fontes de conhecimento, sendo vistos como ambientes de troca de formação entre as pessoas que compartilham apreço pelo consumo de cervejas artesanais. Cita-se ainda a existência de grupos de estudo e confrarias como fonte de conhecimento.

Analisando-se o que diz respeito ao aprendizado, nota-se que o senso de responsabilidade, um dos três pilares para que uma comunidade se estabeleça, se faz presente nas respostas dos entrevistados. O senso de responsabilidade é definido como o sentimento de dever para com a comunidade como um todo e para com os seus membros, que se forma a partir da integração e da retenção de membros e pela assistência ao uso dos produtos da marca (MUÑIZ JR.; O'GUINN, 2001). Dessa forma, ao externalizarem como opções de fonte de conhecimento, bares especializados, ou mais precisamente a "mesa de bar", bem como, grupos de estudo e confrarias, fica clara a integração de membros a assistência relacionada ao consumo de cervejas artesanais. 


\subsection{DIMENSÃO EMOCIONAL}

A capacidade humana de sentir empatia, de compreender os sentimentos próprios e de sentir pelos outros, é uma característica única. A dimensão emocional pode ser compreendida como a conexão harmoniosa, empática ou simpática com o outro, ou ser vista de uma forma congruente com o self (BROOKS, 1989), ou um senso interpessoal genuíno de sensibilidade e preocupação (ASHFORTH; HUMPHREY, 1993). Conforme os trechos analisados no Quadro 2, pode-se dividir a dimensão emocional referente aos consumidores de cerveja artesanal na cidade de Fortaleza em três subprocessos: conexão, identidade e valores.

Conforme indicam Park et al. (2010), a conexão com o produto ou marca seria caracterizada por emoções como afeto, paixão, mas também com memórias, pensamentos e a autoimagem (o que a pessoa é) e a qualidade do relacionamento existente entre a marca e o consumidor. Para esse subprocesso foram questionados os sentimentos que o entrevistado tem para com o produto e se ele se considera um fã de cerveja artesanal.

No que diz respeito à identificação, ela é definida como a extensão em que o consumidor vê a sua própria imagem refletida na imagem da outra parte, ou seja, a identificação com um produto se dá quando o consumidor vê a sua identidade refletida na identidade dele (BAGOZZI; DHOLAKIA, 2006; CARLSON et al., 2008). Para esse subprocesso foi abordado a questão da imagem que o entrevistado deseja ter por meio do consumo de cervejas artesanais.

A internalização de valores se refere ao entendimento e ao comprometimento do membro da comunidade com os valores, crenças e convenções compartilhadas com outros membros, ou seja, é a adoção de guias comuns para atingir objetivos idealizados de forma compartilhada com outros (DHOLAKIA et al., 2004). Neste subprocesso as perguntas buscavam entender se os entrevistados identificavam algum valor ou crença relacionado à bebida, e como ele se sentia fazendo parte desse grupo de consumo.

Quadro 2 - Dimensão emocional.

\begin{tabular}{|c|c|c|}
\hline Subprocesso & Definição & Trecho selecionado \\
\hline \multirow[b]{2}{*}{ Conexão } & \multirow{2}{*}{$\begin{array}{c}\text { Emoções como afeto, } \\
\text { paixão, mas também } \\
\text { com memórias, } \\
\text { pensamentos, e } \\
\text { qualidade do }\end{array}$} & "Eu sinto orgulho de fazer parte desse universo." (E1) \\
\hline & & $\begin{array}{l}\text { "O sentimento que eu tenho quando eu bebo cerveja é basicamente } \\
\text { é nostalgia" (E12) }\end{array}$ \\
\hline
\end{tabular}




\begin{tabular}{|c|c|c|}
\hline & $\begin{array}{l}\text { relacionamento } \\
\text { existente entre o } \\
\text { produto e o }\end{array}$ & $\begin{array}{l}\text { [Quando perguntado o que ele sentia quando bebia cerveja } \\
\text { artesanal] “Amor.” (E16) }\end{array}$ \\
\hline & & $\begin{array}{l}\text { "Cara, só me vem a palavra prazer na minha cabeça, só prazer } \\
\text { realmente, e realização de tá bebendo algo que me faz muito feliz." } \\
\text { (E21) }\end{array}$ \\
\hline & & "É sempre um sentimento de descoberta, é algo novo." (E22) \\
\hline \multirow{5}{*}{ Identificação } & \multirow{5}{*}{$\begin{array}{l}\text { Extensão em que o } \\
\text { consumidor vê a sua } \\
\text { própria imagem } \\
\text { refletida na imagem } \\
\text { produto. }\end{array}$} & "Não espero nada, sou indiferente quanto a isso.” (E2) \\
\hline & & $\begin{array}{l}\text { "Uma pessoa diferente, que curte novas experiências, e que ajuda } \\
\text { outras pessoas a viver essas experiências também." (E3) }\end{array}$ \\
\hline & & $\begin{array}{l}\text { "Sou vista como uma pessoa diferenciada. A sensação que eu tenho } \\
\text { é que as pessoas me enxergam como alguém com mais cultura." } \\
\text { (E10) }\end{array}$ \\
\hline & & $\begin{array}{l}\text { "Alguém de bom gosto, que gosta de descobrir coisas novas e } \\
\text { ajudar outras pessoas a terem essa experiência." (E16) }\end{array}$ \\
\hline & & "Uma pessoa que tem um gosto diferenciado." (E19) \\
\hline \multirow{5}{*}{ Valores } & \multirow{5}{*}{$\begin{array}{c}\text { Entendimento e } \\
\text { comprometimento com } \\
\text { os valores, crenças e } \\
\text { convençõ̃es, adoção de } \\
\text { guias comuns. }\end{array}$} & $\begin{array}{l}\text { "Valores que eu percebo, por exemplo é o que acontece aqui, do } \\
\text { agrupamento das pessoas ficarem na mesma vibe, é você se } \\
\text { harmoniza, você conhece pessoas, quando as pessoas estão aqui } \\
\text { bebendo cerveja elas se desarmam, diferente de outros lugares que } \\
\text { as pessoas olham pra você e já parece que você está invadindo." } \\
\text { (E4) }\end{array}$ \\
\hline & & $\begin{array}{l}\text { "Sim, tem muita gente que diz que a cerveja artesanal tem muito } \\
\text { preconceito com a comercial." (E7) }\end{array}$ \\
\hline & & $\begin{array}{l}\text { "Beba bem beba melhor, cerveja de milho, sempre foi isso aí, até } \\
\text { um dos motivos que eu comecei a beber cerveja artesanal." (E9) }\end{array}$ \\
\hline & & $\begin{array}{l}\text { "Eu acho que é mais essa questão do beba menos beba melhor, de } \\
\text { você beber de forma mais consciente, de você ter prazer de beber } \\
\text { aquela bebida e não de você para se embriagar." (E11) }\end{array}$ \\
\hline & & $\begin{array}{l}\text { "Esse sentimento de colaboração, todo mundo quer colaborar para } \\
\qquad \text { o meio cervejeiro crescer." (E20) }\end{array}$ \\
\hline
\end{tabular}


Conforme os trechos do quadro acima, pode-se notar que a conexão dos entrevistados com a cerveja artesanal é dividida em emoções que remetem a amor, orgulho, alegria e prazer. Além disso, a nostalgia se faz presente entre os consumidores, que relacionam a cerveja com pensamentos que lembram algum momento marcante de suas vidas. Nota-se também uma preocupação com a autoimagem, demostrando o desejo de ser visto como um indivíduo de vanguarda e bom gosto.

Com base nas respostas obtidas, percebe-se que alguns dos entrevistados alcançaram um estágio de proximidade chamado ressonância, que é o nível mais alto de brand equity baseado no consumidor, no qual o valor da marca ou categoria de produto adquire um conjunto de significados mais intensos, incluindo lembranças, experiências de uso, julgamentos e sentimentos, em outras palavras, ressonância se refere à natureza do relacionamento dos consumidores com a marca, na medida em que os consumidores sentem que estão em sintonia com a marca (KELLER, 2003). Tendo em vista que, os sentimentos, uma vez internalizados pelos indivíduos, predispõem sentimentos que amplificam e sustentam o engajamento do consumidor nos discursos e práticas (GOPALDAS, 2014), pressupõe-se que quanto mais alta a ressonância entre os consumidores de cerveja artesanal, mais alto será seu engajamento com o produto.

No que diz respeito à identificação, em torno da cerveja artesanal existe uma áurea que remete à uma experiência sensorial diferenciada, de novidade, de qualidade, e por meio das respostas obtidas é possível notar que os entrevistados se identificam com o produto pelo fato de ele ser diferente, pelo fato de sempre ter algo novo no mercado, e finalmente e por ele ter qualidade, dessa forma corroborando com entendimento de Belk (1988), no qual bens podem ser considerados como uma extensão do self dos indivíduos, o que sugere que a cerveja artesanal também é incorporada por intermédio do consumo para a concepção de identidades que reflitam indivíduos de vanguarda, formadores de opinião, ou de bom gosto. Foi possível notar por meio da pesquisa que existem consumidores que são indiferentes à identificação, bem como identificar uma preocupação com uma percepção pejorativa por parte de outros consumidores de cerveja artesanal ou de pessoas do convívio próximo.

Entende-se, no que se refere aos subprocessos da identificação, que as respostas obtidas estão de acordo com o entendimento de que a identificação é definida como a extensão em que o consumidor vê a sua própria imagem refletida na imagem da outra parte (BAGOZZI; DHOLAKIA, 2006; CARLSON et al., 2008). Ou seja, por meio do consumo de cervejas artesanais, é buscado o autoconceito ideal, que é a concepção da pessoa do modo como gostaria 
de ser percebida (SIRGY, 1982). Ademais vale ressaltar que, também é perceptível o consumo em busca do status, o que colabora com o pensamento de McCracken (2003), que afirma que objetos serviriam como demonstradores do status que se goza na sociedade, e de Belk (1988), afirma que os indivíduos seriam a soma de todas as suas posses.

No contexto da internalização de valores, na pesquisa realizada foram notadas algumas convicções adotadas e compartilhadas com os demais membros, como, por exemplo, a crença no consumo de um produto superior, de acordo com a qual as cervejas mainstream não são consideradas cervejas de verdade, de que ao provar cerveja artesanal o indivíduo se tornará um consumidor do produto, um senso de responsabilidade para com a sociedade por meio do consumo moderado da bebida, e, por fim, a valorização do produto local. A valorização do grupo é outro ponto de destaque no que diz respeito aos valores compartilhados. Pode-se afirmar que alguns dos entrevistados ainda não internalizaram os valores e as crenças compartilhadas por outros consumidores mais experientes, em alguns casos devido ao baixo grau de relacionamento com a comunidade, ou à falta de interesse nela, como também ao pouco tempo de experiência com o produto.

Observou-se também que o uso de jargões e modos únicos de expressão da comunidade de marca referente à cerveja artesanal são tantos que se misturam entre as diversas categorias de consumidores, porém quanto maior o envolvimento com o produto, maior o aprendizado e uso de vocabulários e jargões exclusivos de quem é consumidor do meio. Percebe-se que os consumidores de cervejas comuns foram denominados na seguinte pesquisa de "Brahmeiros", ou seja, àqueles que consomem cerveja mainstream e eventualmente cerveja artesanal, e por isso não postulam participação no grupo (MENEZES FILHO et al., 2020). Por fim, foi identificado que alguns entrevistados ainda não se sentem inseridos, ou não sentem interesse em participar da comunidade.

\subsection{DIMENSÃO COMPORTAMENTAL}

A dimensão comportamental pode ser entendida como um conjunto de manifestações comportamentais do indivíduo que têm como foco um produto ou marca. Estas ações podem estar contextualizadas em uma relação consumidor-produto ou consumidor-consumidor (van Doorn, et al., 2010). Conforme os trechos analisados no Quadro 3, pode-se dividir a dimensão comportamental referente aos consumidores de cerveja artesanal na cidade de Fortaleza em três subprocessos: lealdade, interação e cocriação. 
A lealdade é um dos constructos que são apontados como consequência do engajamento (BRODIE et al., 2011; HOLLEBEEK, 2011a). Conforme Oliver (1999), a lealdade proveniente do consumidor pode ser encarada como um comprometimento profundo desse em comprar ou usar novamente um produto ou um serviço. Para este subprocesso questionou-se a respeito do grau de lealdade dos entrevistados, buscando entender os motivos de uma menor ou maior lealdade para com o produto.

É por meio da interação que a comunidade se desenvolve e se sustenta, já que os membros compartilham informações e experiências (CASALÓ et al., 2007), aumentando o entendimento da marca (BAGOZZI; DHOLAKIA, 2006), e os benefícios percebidos pelos membros (KUO; FENG, 2013), o que acaba promovendo também a identificação com a comunidade e por consequência o valor da comunidade (CASALÓ et al., 2007; 2008).

Já o termo cocriação apontado por Brodie et al. (2011), definido como o nível de percepção de valor criado na mente do cliente em decorrência de atividades interativas, conjuntas e/ou personalizadas para e com os stakeholders (DALL'OLMO; CHERNATONY, 2000; PRAHALAD; RAMASWAMY, 2004). Para esse subprocesso foi questionado se o entrevistado já colaborou para o melhoramento do produto ou do serviço relacionado a este.

Quadro 3 - Dimensão comportamental.

\begin{tabular}{|c|c|c|}
\hline Subprocesso & Definição & Trecho selecionado \\
\hline \multirow{4}{*}{ Lealdade } & \multirow{4}{*}{$\begin{array}{l}\text { Comprometimento } \\
\text { profundo desse em } \\
\text { comprar ou usar } \\
\text { novamente um } \\
\text { produto ou um } \\
\text { serviço. }\end{array}$} & $\begin{array}{c}\text { "Eu acho que se apegar a uma marca, a um estilo, é perder o que a cerveja } \\
\text { tem de melhor, que é a questão da variedade, essa infinita possibilidade de } \\
\text { experiência." (E1) }\end{array}$ \\
\hline & & $\begin{array}{l}\text { “Já fui menos fiel, acho que já passei da fase de sair provando tudo feito } \\
\text { um doido, lógico que sempre haverá novidades, mas hoje é praticamente } \\
\text { impossível provar tudo do mercado, então vou com calma nas escolhas, } \\
\text { tenho sim minhas cervejas favoritas, meus estilos favoritos, e me satisfaço } \\
\text { com isso.” (E16) }\end{array}$ \\
\hline & & $\begin{array}{l}\text { “Acho que me considero, sou um fervoroso da escola inglesa, adoro escola } \\
\text { inglesa, eu consumo muito Barleywine, Imperial Stout, Fuller's. eu tenho } \\
\text { sim dois ou três estilos que são cervejas mais alcoólicas que eu consumo } \\
\text { mais que as outras” (E21) }\end{array}$ \\
\hline & & $\begin{array}{l}\text { “As IPAS, e tem IPAS, que moram no meu coração, copo por exemplo a } \\
\text { IPA Hunters da Founders, que eu não deixo faltar lá em casa.” (E23) }\end{array}$ \\
\hline
\end{tabular}




\begin{tabular}{|c|c|c|}
\hline \multirow{4}{*}{ Interação } & \multirow{4}{*}{$\begin{array}{c}\text { Senso de } \\
\text { pertencimento e } \\
\text { comunidade. } \\
\text { Interação entre os } \\
\text { consumidores, } \\
\text { socialização. }\end{array}$} & $\begin{array}{c}\text { "Eu acho que isso, com aqueles que não conhecem ou estão conhecendo a } \\
\text { gente fica grato por ajudar e ver em ver as reações, e com os que já } \\
\text { conhecem gente troca informações. " (E5) }\end{array}$ \\
\hline & & $\begin{array}{l}\text { “Geralmente num bar você chega só, mas num bar de cerveja artesanal } \\
\text { você sempre acaba conversando com a galera, e no final da noite está todo } \\
\text { mundo junto conversando um pouco disso um pouco daquilo sobre } \\
\text { cerveja. É aquele sentimento de acolhimento, uma grande família.” (E9) }\end{array}$ \\
\hline & & $\begin{array}{l}\text { "Eu acho interessante, porque eu aprendi muito, por exemplo, análise } \\
\text { sensorial, eu aprendi muito a identificar aromas e sabores, que era algo } \\
\text { que eu não fazia antes de conhecer cerveja artesanal e ter contato com } \\
\text { outras pessoas que compartilhavam desse interesse." (E12) }\end{array}$ \\
\hline & & $\begin{array}{l}\text { "Me relaciono bem, a gente faz troca de produtos, trocas de cerveja, de } \\
\text { conhecimento, compras em conjunto." (E19) }\end{array}$ \\
\hline \multirow{4}{*}{ Cocriação } & \multirow{4}{*}{$\begin{array}{l}\text { Contribuição dos } \\
\text { consumidores no } \\
\text { desenvolvimento da } \\
\text { marca. }\end{array}$} & $\begin{array}{l}\text { “Já, mas pouca coisa, uma dica ou outra nos serviços de bares e } \\
\text { restaurantes, me lembro que disse para usarem o copo ideal, também já dei } \\
\text { dica de temperatura de serviço." (E3) }\end{array}$ \\
\hline & & $\begin{array}{l}\text { “Quando eu trabalhava na cervejaria eu sempre estava em contato com o } \\
\text { pessoal da produção, quando eu achava que tinha algum erro na cerveja eu } \\
\text { passava para eles, eu trocava ideias sobre receitas, enfim.” (E7) }\end{array}$ \\
\hline & & $\begin{array}{c}\text { “Assim, eu acredito que eu não ter tanto conhecimento assim, eu não me } \\
\text { sinto nessa facilidade, nessa liberdade de trocar essas ideias assim, então } \\
\text { não.” (E8) }\end{array}$ \\
\hline & & $\begin{array}{l}\text { "Já fui chamado para degustar algumas cervejas de algumas cervejarias e } \\
\text { bares com o intuito de ver se estavam em condições boas." (E19) }\end{array}$ \\
\hline
\end{tabular}

No que diz respeito à lealdade, pode-se perceber no quadro acima, que entre os respondentes, existem diferentes níveis de lealdade para com o produto. Alguns demonstram lealdade total a um estilo, rótulo ou cervejaria, outros não demonstram lealdade nenhuma pois estão sempre em busca de novidades, e por fim tem-se um meio termo, no qual o consumidor apesar de ter preferências não se fecha para novas experiências.

Conforme a pesquisa, pode-se entender a lealdade como um processo dinâmico, que pode ser compreendido em três etapas. A primeira seria a lealdade cognitiva, diretamente ligada aos custos e aos benefícios percebidos pelo consumidor. A segunda seria a lealdade afetiva, que 
se caracteriza pela formação de um afeto ou atitude em relação ao produto após sucessivas experiências. E, por fim, tem-se a lealdade conativa, que implica em recomprar um produto específico e a consistência ou estabilidade nas crenças relativas a este.

O subprocesso relativo à interação foi identificado de duas maneiras: a interação membro-membro e o envolvimento membro-atividade. A interação membro-membro se refere à extensão da interação entre os membros caracterizada pela troca de informações, enquanto o envolvimento membro-atividade se refere à intensidade com a qual o membro participa das atividades da comunidade. No que diz respeito à diferenciação e a separação entre consumidores e cerveja artesanal, fica evidente por meio de trechos das entrevistas, a consciência dos entrevistados de quem é membro e de quem não é membro da comunidade de consumo, bem como é perceptível o preconceito entre os consumidores de cerveja artesanal e os consumidores de cerveja comum

Percebe-se também, que a consciência compartilhada, uma das características das comunidades de consumo (MUNIZ JR.; O'GUINN, 2001), que pode ser interpretada como a identificação com a comunidade (BAGOZZI; DHOLAKIA, 2006), se faz presente nas respostas obtidas de boa parte dos entrevistados quando se observa a manifestação do sentimento de bemestar, o sentimento de pertencimento compartilhado que possibilita a diferenciação e a separação de quem é membro e de quem não é membro da comunidade referente à cerveja artesanal.

O último subprocessos analisado nessa dimensão é o que se refere à cocriação. De acordo com as entrevistas, se destacam três tipos de co-desenvolvimento do produto, são eles: sugestões no serviço, participação nas receitas, e avaliação do produto por meio de degustação. Vale ressaltar que alguns entrevistados responderam que não possuem esse tipo de relação com o produto em virtude do seu baixo nível de conhecimento a respeito de cervejas artesanais.

De acordo com Brodie et al. (2011), o engajamento do cliente é um estado psicológico que ocorre por meio da virtude de interatividade e da cocriação de experiência do cliente com um agente/objeto focal em uma relação focal de serviço. Percebe-se então, por meio das entrevistas, que alguns dos consumidores de cerveja artesanal colaboraram com a criação de produtos e experiências junto de estabelecimentos como cervejarias, bares, e lojas especializadas, corroborando com o entendimento que a cocriação de valor baseia-se em uma premissa fundamental: a criação de valor deixa de ser um processo unilateral para tornar-se bilateral, já que o cliente passa a desempenhar papel determinante (TROCCOLI, 2009). Notase também que o acúmulo de conhecimento e de experiências com o produto interfere no nível 
de cocriação por parte do consumidor, no qual consumidores mais experientes e que detém maior conhecimento, normalmente exercem de maneira mais intensa o co-desenvolvimento de valores.

\section{DISCUSSÃO}

O presente estudo reforça a perspectiva multidimensional de engajamento do consumidor proposta por Brodie et al. (2011), bem como corrobora com o entendimento de alguns autores que sugerem que à medida que o consumidor se engaja mais com um consumo específico, ele se integra mais com a comunidade (STOKBURGERSAUER, 2010), se identifica mais com a comunidade (VIVEK et al., 2012), internaliza mais os valores dessa comunidade (BAGOZZI; DHOLAKIA, 2002); e tem maior senso de responsabilidade com os demais membros (ALGESHEIMER et al., 2005). Além disso, a presente pesquisa contribui para teoria e prática à medida que identifica os subprocessos que suportam o engajamento do consumidor, especificamente na cultura de consumo da cerveja artesanal. Com esta perspectiva processual, entende-se o engajamento do consumidor como algo mais dinâmico, que precisa ser observado sob a visão multidimensional.

No que se refere a subprocessos de engajamento, a presente pesquisa identificou nove opções relativas aos consumidores na cidade de Fortaleza; são eles: (i) Aprendizado, relativo à absorção de conhecimento; (ii) Advocacia, que se refere à defesa e recomendação do produto; (iii) Rituais, que diz respeito à transmissão interna e externa dos significados da comunidade; (iv) Conexão, que versa sobre as emoções e a qualidade do relacionamento existente entre o consumidor e o produto; (v) Identidade, que diz respeito à identidade do consumidor refletida no produto; (vi) Valores, que se refere ao entendimento e ao comprometimento com os valores e crenças; (vii) Cocriação, que é relativo ao nível de percepção de valor criado na mente do cliente em decorrência de atividades interativas; (viii) Lealdade, que reflete a probabilidade do consumidor mudar ou não de marca ou de produto; e (ix) Interação, que diz respeito à socialização.

Tais subprocessos se relacionam com os cinco subprocessos do engajamento propostos por Brodie et al. (2013), a saber: (a) aprender, que se refere a adquirir competências cognitivas; (b) compartilhar informações, conhecimento e experiências por meio de contribuições ativas; (c) advogar em favor da marca, a recomendando ativamente; (d) socializar, adquirindo e desenvolvendo atitudes, normas e linguagens; e (e) codesenvolver, contribuindo para a organização, auxiliando em processos de desenvolvimento de produtos, serviços, marcas e (c) (1) $(9)$ REAd | Porto Alegre - Vol. 27 - N.o 2 - Maio / Agosto 2021 - p. 547-578. 
significado de marca. Todavia, os subprocessos propostos no presente estudo, ampliam aqueles propostos por Brodie et al. (2013) uma vez que demonstram de forma mais direta e relacionada como cada subprocessos se conecta com uma dimensão de engajamento. Tal fato representa o atendimento da pergunta de pesquisa e a principal contribuição teórica desta pesquisa.

No que se refere à CCT, a presente pesquisa sugere a existência de uma cultura de consumo relacionada à cerveja artesanal na cidade de Fortaleza, na medida em que os estudos realizados forneceram evidências que permitiram sugerir a presença de um subgrupo diverso da sociedade que se auto seleciona com base em um compromisso compartilhado com a atividade de consumo relacionada à cerveja artesanal. Por meio das informações obtidas, observou-se a existência de um arcabouço hierárquico identificável, um ethos singular (OLIVEIRA et al., 2018), assim como, rituais, linguagem e modos únicos de expressão simbólica relacionados ao consumo de cerveja artesanal em Fortaleza, que de acordo com Schouten e McAlexander (1995), são pré-requisitos de uma cultura de consumo.

\section{CONCLUSÃO}

Acredita-se que a presente pesquisa trouxe contribuições significativas para o campo da CCT, mais especificamente ao grupo temático denominado de "cultura de mercado", que investiga a forma como alguns produtos e experiências podem unir grupos em espécies de culturas ou subculturas de consumo, ao sugerir a existência de uma cultura de consumo relacionada à cerveja artesanal. Entende-se também que a pesquisa colabora com os estudos de engajamento do consumidor ao propor uma consonância entre o engajamento do consumidor e a cultura de consumo, por meio dos subprocessos identificados.

Dessa forma, o presente estudo sugere nove subprocessos de engajamento (Quadro 4). Tais subprocessos poderão ser estendidos para outros estudos relacionado ao engajamento, bem como utilizadas em outras pesquisas relacionadas à cultura de consumo em questão ou outras tantas. Do ponto de vista da gestão de marcas, os achados colaboram ao apontar para subprocessos que podem nortear análises de segmentação deste mercado, auxiliando organizações do setor na busca de estratégias de relacionamento com o público-alvo. Dessa forma, o presente estudo pode ser utilizado como inspiração para estratégias de negócios, na medida em que é possível identificar e consistentemente comunicar valores que conectam cada perfil de consumidor com o produto. 
Quadro 4 - Subprocessos de engajamento relativo aos consumidores de cerveja artesanal.

\begin{tabular}{|c|c|}
\hline Subprocesso & O que significa para o campo de consumo de cervejas artesanais \\
\hline Aprendizado & $\begin{array}{l}\text { - O apreciador de cerveja artesanal utiliza o conhecimento que possui a respeito do } \\
\text { produto para escolher a cerveja mais adequada ao seu paladar, ou para degustar e } \\
\text { harmonizar da maneira correta; } \\
\text { - As aptidões cognitivas são utilizadas para influenciar ou ajudar outros indivíduos a } \\
\text { experimentar o produto; } \\
\text { - Os consumidores buscam conhecimento por meio de livros, blogs, ou sites } \\
\text { especializados, e até mesmo aplicativos. } \\
\text { - As casas especializadas, foram consideradas uma das mais relevantes fontes de } \\
\text { conhecimento. }\end{array}$ \\
\hline Advocacia & $\begin{array}{l}\text { - Consumidores "advogados" tendem a gastar mais do que a média dos consumidores } \\
\text { da categoria; } \\
\text { - Recomendam o produto aos amigos ou compartilham sua opinião e experiência nas } \\
\text { redes sociais; } \\
\text { - Participam de fóruns, dão sugestões de ações às cervejarias; }\end{array}$ \\
\hline Rituais & $\begin{array}{l}\text { - Rituais estão relacionados ao momento da compra, ao momento da degustação, e ao } \\
\text { compartilhamento destes momentos para demais apreciadores; } \\
\text { - Consumidores tratam elementos da cerveja como tampinhas, garrafas e rótulos como } \\
\text { itens colecionáveis; } \\
\text { - Vale ressaltar que o ato de beber e compartilhar informações com outros membros } \\
\text { também foi citado como ritual, dando-se destaque para as confrarias ou os Bottle } \\
\text { Share. }\end{array}$ \\
\hline Conexão & $\begin{array}{l}\text { - O sentimento pelo produto foi externalizado também por meio de camisas e bonés } \\
\text { referentes ao produto, coleções de copos, rótulos e tampinhas, tatuagens e até mesmo } \\
\text { pets com nomes de cerveja. }\end{array}$ \\
\hline Identidade & $\begin{array}{l}\text { - Os consumidores se identificam com o produto pelo fato de ele ser diferente, pelo } \\
\text { fato de sempre ter algo novo no mercado, e finalmente e por ele ter qualidade; } \\
\text { - A cerveja artesanal é contraída por intermédio do consumo para a concepção de } \\
\text { identidades que reflitam indivíduos de vanguarda, formadores de opinião, ou de bom } \\
\text { gosto; } \\
\text { - É perceptível a relação do consumo de cerveja artesanal e da busca por status. }\end{array}$ \\
\hline Valores & $\begin{array}{l}\text { - Crença no consumo de um produto superior, no qual as cervejas mainstream não são } \\
\text { consideradas cervejas de verdade; } \\
\text { - Crença de que ao provar cerveja artesanal o indivíduo se tornará um consumidor do } \\
\text { produto; } \\
\text { - Senso de responsabilidade para com a sociedade por meio do consumo moderado da } \\
\text { bebida; }\end{array}$ \\
\hline
\end{tabular}




\begin{tabular}{|l|ll|}
\hline & $\bullet$ & A valorização do produto local; \\
\hline Cocriação & A valorização do grupo de consumidores de cerveja artesanal. \\
\hline Lealdade & $\begin{array}{l}\text { Destacam-se três tipos de co-desenvolvimento do produto, são eles: sugestões no } \\
\text { serviço, participação nas receitas, e avaliação do produto por meio de degustação; }\end{array}$ \\
Alguns dos consumidores de cerveja artesanal colaboraram com a criação de \\
produtos e experiências junto a estabelecimentos como cervejarias, bares, e lojas \\
especializadas; \\
O acúmulo de conhecimento e de experiências com o produto interfere no nível de \\
cocriação por parte do consumidor.
\end{tabular}

Apesar de este estudo ter oferecido contribuições no ponto de vista acadêmico e prático, não pode deixar de se salientar que existiram algumas limitações que podem ser consideradas. A primeira se refere ao fato de que a maioria dos trabalhos relacionados à cerveja artesanal seguem uma visão focada em uma abordagem behaviorista, ou seja, deixam de lado todo o complexo sistema cultural e se restringem a analisar o consumo como fato econômico e individual. Além disto, vale salientar que pesquisas de segmentação de mercado possuem natureza quantitativa e por conseguinte, os resultados devem ser empregados com discernimento na elaboração de estratégias de segmentação.

Como sugestões para investigações futuras, tem-se a possibilidade de uma pesquisa quantitativa, bem como adaptar e aplicar este estudo em outras categorias de bebidas, como por exemplo, cafés gourmet, cachaças artesanais, etc. Fica a expectativa de que novos estudos sobre (sub)culturas de consumo utilizem destas contribuições e que possam ser descobertos novos aspectos que ampliem a discussão sobre subprocessos fornecendo novos insights ao campo da cultura e consumo, bem como pesquisas relacionadas com o engajamento do consumidor, e ao estudo da cerveja artesanal. 


\section{REFERÊNCIAS}

ABRACERVA. Associação Brasileira de Cerveja Artesanal. Disponível em: http://abracerva.com.br/. Acesso em: 24 dez. 2018.

ALGESHEIMER, R.; DHOLAKIA, U.; HERRMANN, A. The social influence of brand community: evidence from European car clubs. Journal of Marketing, v. 69, n. 3, p. 19-30, 2005 .

ARNOULD, E. J.; THOMPSON, C. J. Consumer culture theory (CCT): twenty years of research. Journal of Consumer Research, Gainesville, v. 31, n. 4, p. 868-882, 2005.

ASHFORTH, B. E.; HUMPHREY, R. H. Emotional Labor in Service Roles: The Influence of Identity. Academy of Management Review, v. 18, n. 1, p. 88-115, 1993.

BAGOZZI, R. P.; DHOLAKIA, U. M. Antecedents and purchase consequences of customer participation in small group brand communities. International Journal of Research in Marketing, v. 23, n. 1, p. 45-61, 2006.

BARBOSA, L. Sociedade de consumo. Rio de Janeiro: Jorge Zahar, 2004.

BARDIN, L. Análise de conteúdo. Lisboa: Edições 70, 2009.

BELK, R. W. Possessions and extended self. Journal of Consumer Research, Gainesville, v. 15, n. 2, p. 139-168, 1988.

BELTRAMELLI, M. Cervejas, brejas e birras: um guia completo para desmistificar a bebida mais popular do mundo. 2. ed. São Paulo: Leya, 2015.

BREWER'S ASSOCIATION. Disponível em: https://www.brewersassociation.org/. Acesso em: 28 mar. 2018.

BRODIE, R. J. et al. Consumer engagement in a virtual brand community: An exploratory analysis. Journal of Business Research, v. 66, n. 1, p. 105-114, 2013.

BRODIE, R. J. et al. Customer Engagement: Conceptual Domain, Fundamental Propositions, and Implications for Research. Journal of Service Research, v. 14, n. 3, p. 252- 271, 2011.

BROOKS, M. Instant rapport. New York: Warner Brooks, 1989.

CARLSON, B. D.; SUTER, T. A.; BROWN, T. J. Social versus psychological brand community: The role of psychological sense of brand community. Journal of Business Research, v. 61, n. 4, p. 284-291, 2008.

CASALÓ, L. V.; FLAVIÁN, C.; GUINALÍU, M. The impact of participation in virtual brand communities on consumer trust and loyalty: The case of free software. Online Information Review, v. 31, n. 6, p. 775-792, 2007.

CASAlÓ, L. V.; FLAVIÁN, C.; GUINALÍU, M. Promoting Consumer's Participation in Virtual Brand Communities: A New Paradigm in Branding Strategy. Journal of Marketing Communications, v. 14, n. 1, p. 19-36, 2008. 
COOPER, D. R.; SCHINDLER, P. S. Métodos de pesquisa em administração. 7. ed. Porto Alegre: Bookman, 2003.

COVA, B.; PACE, S.; PARK, D. J. Global brand communities across borders: The Warhammer case. International Marketing Review, v. 24, n. 3, p. 313-329, 2007.

DALl'OLMO, F, CHERNATONY, L.: The Service Brand As Relationships Builder. British Journal of Management, v.11, p.137-150, 2000.

DESJEUX, D. O Consumo: Abordagens em Ciências Sociais. Maceió: EDUFAL, 2011.

DINIZ, J. M. A.; SILVA, M. E. Meu perfil de Facebook me representa! um estudo da relação entre feminismo e o eu estendido digital. Revista Alcance (Online), v. 24, n. 3, p. 309-328. 2017.

DHOLAKIA, U.; BLAZEVIC, V.; WIERTZ, C. Communal service delivery: how customers benefit from participation in firm-hosted virtual P3 communities. Journal of Service Research, v. 12, n. 2, p. 208-226, 2009.

ESCALAS, J. E.; BETTMAN, J. R. Self-construal, Reference Groups, and Brand Meaning. Journal of Consumer Research, v. 32, 2005.

FOURNIER, S.; LEE, L. Getting brand communities right. Harvard Business Review, v. 87, n. 4, 2009.

FÜLLER, J.; MATZLER, K.; HOPPE, M. Brand community members as a source of innovation. Journal of Product Innovation Management, v. 25, n. 6, p. 608-619, 2008.

GAIÃO, B. F. S.; SOUZA, I. L.; LEÃO, A. L. S. Consumer culture theory (CCT) já é uma escola de pensamento em marketing? RAE - Revista de Administração de Empresas, v. 52, n. 3, 2012.

GAMBETTI, R.C.; GRAFFIGNA, G.; BIRAGHI, S. The Grounded Theory approach to consumer--brand engagement: the practitioner's standpoint. International Journal of Market Research, v. 54 n. 5, p. 659-687, 2012.

GOPALDAS, A. Marketplace sentiments. Journal of Consumer Research. v. 41, n. 4, p. 995 1014,2014

HARRINGTON, J. H. Aperfeiçoando processos empresariais: estratégia revolucionária para o aperfeiçoamento da qualidade, da produtividade e da competitividade. São Paulo: Makron Books, 1993.

HOLBROOK, M. B.; HIRSCHMAN, E. C. The experiential aspects of consumption: consumer fantasy, feelings and fun. Journal of Consumer Research, v. 9, n. 2, 1982, p. 132- 140.

HOLLEBEEK, L. D. Demystifying customer brand engagement: Exploring the loyalty nexus. Journal of Marketing Management, v. 27, n. 7-8, p. 785-807, 2011a. 
HOLLEBEEK, L. D. Exploring customer brand engagement: definition and themes. Journal of Strategic Marketing, v. 19, n. 7, p. 555-573, $2011 \mathrm{~b}$.

HOLLEBEEK, L. D.; SRIVASTAVA, R. K.; CHEN, T. SD logic-informed customer engagement: integrative framework, revised fundamental propositions, and application to CRM. Journal of the Academy of Marketing Science, v. 47, n. 1, p. 161-185, 2019.

KELLER, K. Brand Synthesis: The Multi-Dimensionality of Brand Knowledge. Journal of Consumer Research, v. 29, 4, p. 595-600, 2003.

KOZINETS, R. V. Utopian Enterprise: Articulating the Meaning of Star Trek's Culture of Consumption. Journal of Consumer Research, v. 28, p. 67-89, 2001.

KUMAR, V.; PANSARI, A. Competitive advantage through engagement. Journal of Marketing Research, v. 53, 4, p. 497-514, 2016.

KUO, Y.-F.; FENG, L.-H. Relationships among community interaction characteristics, perceived benefits, community commitment, and oppositional brand loyalty in online brand communities. International Journal of Information Management, v. 33, n. 6, p. 948-962, 2013.

LEE, Y. H.; CHANG, W. L. The effect of interpersonal relationships on brand community. International Journal of Digital Content Technology and its Applications, v. 5, n. 7, p. 297 $305,2011$.

LIPOVETSKY, G. O império do efêmero: a moda e seu destino nas sociedades modernas. São Paulo: Companhia das Letras, 2004.

MADUPU, V.; COOLEY, D. O. Antecedents and Consequences of Online Brand Community Participation: A Conceptual Framework. Journal of Internet Commerce, v. 9, n. 2, p. 127147, 2010a.

MAFFESOLI, M. O tempo das tribos: o declínio do individualismo nas sociedades pósmodernas. Rio de Janeiro: Forense Universitária, 2014.

MAPA. Ministério da Agricultura, Pecuária e Abastecimento. Disponível em: http://www.agricultura.gov.br/. Acesso em: 27 Nov. 2020.

MARCHI, G.; GIACHETTI, C.; DE GENNARO, P. Extending lead-user theory to online brand communities: The case of the community Ducati. Technovation, v. 31, n.8, 2011.

MARRA, G., DAMACENA, C. Engajamento do consumidor: revisão teórica do conceito e seus antecedentes. REGE - Revista de Gestão, v. 20, n. 2, p. 233-249, 2013.

MATTAR, F. N. Pesquisa de marketing: metodologia, planejamento, execução e análise. $7^{\text {a }}$. ed. São Paulo: Atlas, 2014.

MAYRING, P. Qualitative content analysis. A companion to qualitative research, 1(2), p.159176, 2014. 
MCALEXANDER, J.; SCHOUTEN, J.; KOENIG, H. Building brand community. Journal of Marketing, v. 66, n.1, p. 38-54, 2002.

MCCRACKEN, G. Cultura e Consumo: novas abordagens ao caráter simbólico dos bens e das atividades de consumo. Rio de Janeiro: MAUAD, 2003.

MENEZES FILHO, J.G.; SILVA, M.E.; CASTELO, J. S. F. A Constituição Identitária do Consumidor de Cerveja Artesanal na Cidade de Fortaleza. Brazilian Business Review, v. 17, n. 4, p.381-398. 2020.

MORADO, R. Larouse da cerveja. São Paulo: Alaúde, 2017.

MUÑIZ, A.; O'GUINN, T. Brand community and the sociology of brands. Journal of Consumer Research, v. 27, n. 4, p. 412-432, 2001.

MUÑIZ, A.; SCHAU, H. Religiosity in the abandoned apple Newton brand community. Journal of Consumer Research, v. 31, p. 737- 47, 2005.

OBILO, O. O; CHEFOR, E.; SALEH, A. Revisiting the consumer brand engagement concept. Journal of Business Research, p. 1-10, 2020.

OLIVEIRA, R. S., SILVA, M. E., GAIÃO, B. F. S. Orgulho de ser nordestino!: Um estudo sobre ethos compartilhado por seguidores em uma página do Facebook. GESTÃO. Org, v. 16, n. 2, p. 182-193. 2018.

OLIVER, R. L. Whence consumer loyalty? Journal of Marketing, v. 63, p. 33-44, 1999.

PARK, C., MCLNNIS, D., PRIESTER, J., EISINGERICH, A., IACOBUCCI, D. Brand Attachment and Brand Attitude Strength: Conceptual and Empirical Differentiation of Two Critical Brand Equity Drivers. Journal of Marketing, v. 74, 2010.

PRAHALAD, C. K.; RAMASWAMY, V. Co-creation Experiences: the next practice in value creation. Journal of Interactive Marketing, v. 18, n. 3, 2006.

SCHAU, H. J.; MUÑIZ JR, A. M.; ARNOULD, E. J. How brand community practices create value. Journal of Marketing, v. 73, n. 5, p. 30-51, 2009.

SCHOUTEN, J. W.; MCALEXANDER J. H. Subcultures of consumption: an ethnographic of the new bikers. Journal of Consumer Research, v. 22, n. 1, p. 43-61, 1995.

SCHOUTEN, J.; McALEXANDER, J.; KOENIG, H. Transcendent customer experience and brand community. Journal of the Academy of Marketing Science, v. 35, n. 3, p. 357-368, 2007.

SINDICERVA. Sindicato Nacional da Indústria da Cerveja. Disponível em: https://www.sindicerv.com.br/o-setor-em-numeros/. Acesso em: 22 nov. 2020.

SILVA, M. E.; CAMPOS, S. A. P. Stakeholders' Dialogue and Engagement. Responsible Consumption and Production - SAGE, p. 691-699. 2020. DOI: 10.1007/978-3-319-95726-5_14 
SIRGY, M. J. Self-concept in consumer behavior: a critical review. Journal of Consumer Research. v. 9., p. 287-300, 1982.

SLATER, D. Cultura do consumo \& modernidade. São Paulo: Nobel, 2002.

SOLOMON, M. O Comportamento do Consumidor: Comprando, Possuindo e Sendo. 9. ed. Porto Alegre: Bookman, 2010.

SOUZA, I. L., GAIÃO, B. F. S., SANTOS SILVA, J.; SOUZA LEÃO, A. L. M. Uma abordagem alternativa para a pesquisa do consumidor: adoção da Consumer Culture Theory (CCT) no Brasil. Revista Alcance, v. 20, n. 3, p. 383-399. 2013.

STOKBURGERSAUER, N. Brand community: drivers and outcomes. Psychology \& Marketing. v. 24, n. 4, p. 347-368, 2010.

STORY, V.; HART, S.; O'MALLEY, L. Relational resources and competences for radical product innovation. Journal of Marketing Management, v. 25, 2009.

TAJFEL, H.; TURNER, J. C. An integrative theory of inter-group conflict. In AUSTIN, W. G.; WORCHEL S. The social psychology of inter-group relations.Monterey: Brooks/Cole, p. 3347, 1985 .

THERKELSEN, A.; GRAM, M. The meaning of holiday consumption. Journal of Consumer Culture, v. 8, n. 2, p. 269-292, 2008.

TROCCOLI, I. R. Co-criacao de Valor e Fidelização de Clientes: Uma Visão Integrada. Inter Science Place, 2009.

VAN DOORN, J. et al. Customer Engagement Behavior: Theoretical Foundations and Research Directions. Journal of Service Research, v. 13, n. 3, 2010.

VIVEK, S. D. A scale of consumer engagement. 2009. Tese (Doctorate in Philosophy) - The University of Alabama, Alabama, 2009.

VIVEK, S. D.; BEATTY, S. E.; MORGAN, R.M. Customer Engagement: Exploring Customer Relationships Beyond Purchase. Journal of Marketing Theory and Practice, v. 20, n. 2, 2012. 